\title{
Erythema dyschromicum perstans (ashy dermatosis) during the treatment with infliximab in a child with Crohn disease
}

\author{
Michał Sobjanek', Magdalena Lange', Igor Michajłowski', Joanna Lakomy², Roman Nowicki' \\ 'Department of Dermatology, Venereology and Allergology, Medical University of Gdansk, Poland \\ 2Department of Patomorphology, Medical University of Gdansk, Poland
}

Przegl Dermatol 2014, I0I, 27-30

DOI: 10.5 | |4/dr.2014.41068

KEY WORDS:

erythema dyschromicum perstans, ashy dermatosis, Crohn disease, infliximab.

\section{ADRESS FOR CORRESPONDENCE:}

Michał Sobjanek MD, PhD

Department of Dermatology,

Venereology and Allergology

Medical University of Gdansk

7 Dębinki St, 80-211 Gdansk,

Poland

phone: +48583492580

e-mail: sobjanek@wp.pl

\begin{abstract}
Introduction. Erythema dyschromicum perstans (EDP) or ashy dermatosis is a rare, benign acquired disease characterized by macular hyperpigmentations. The cause of EDP is unclear although some drugs, toxic agents and internal disorders have been associated with this dermatosis.
\end{abstract}

Objective. Presentation of the first case of the association between EDP and Crohn disease treated with infliximab.

Case report. We present a case of a 15-year-old boy with Crohn disease who was treated with infliximab. During the treatment asymptomatic, hyperpigmented macules on the trunk were observed. Based on clinical and histopathological features the diagnosis of erythema dyschromicum perstans was established.

Conclusions. Erythema dyschromicum perstans may be associated with Crohn disease and infliximab.

\section{INTRODUCTION}

Erythema dyschromicum perstans (EDP) is an acquired, mild dermatosis of unknown aetiology, rare in the Caucasian population. The condition is characterized by greyish ash-coloured patchy eruptions. The etiopathogenesis of EDP is not completely understood $[1,2]$. There is a known link between EDP and other disorders and medications, however EDP has not so far been reported as accompanying inflammatory bowel diseases or biological therapy.

\section{OBJECTIVE}

To present a previously unreported association between EDP and Crohn's disease (CD) treated with infliximab.

\section{CASE REPORT}

A 15-year-old boy received consultation at the Department of Dermatology, Venereology and Allergology of the Medical University of Gdansk in May 2011 due to greyish ash-coloured patchy eruptions located on the trunk (Figs. $1 \mathrm{~A}$ and $1 \mathrm{~B}$ ), which had been observed since 2009. The patient reported no other skin conditions. In September 2007, the patient began therapy with infliximab (receiving a total of 17 doses of the drug) due to $\mathrm{CD}$ which was diagnosed in 2002. No extraintestinal manifestations of the disease were observed. Due to remission of $\mathrm{CD}$, the drug was discontinued in March 2011. Aside from the history of gastrointestinal disorder, the emergence of cutaneous lesions could not be correlated with any other factors (medications, toxic substances, concomitant diseases). A histopathological assessment 
A

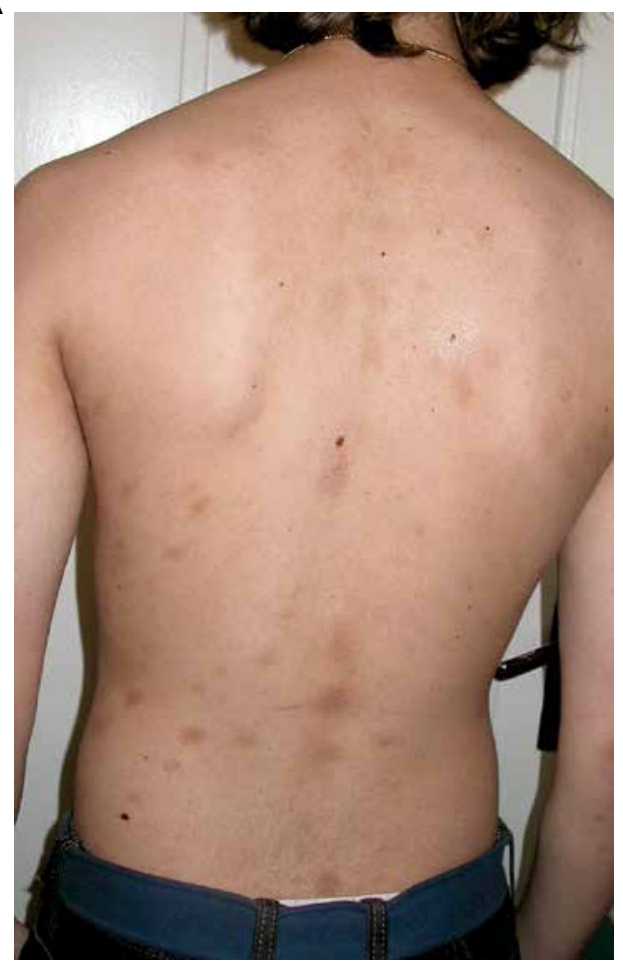

B

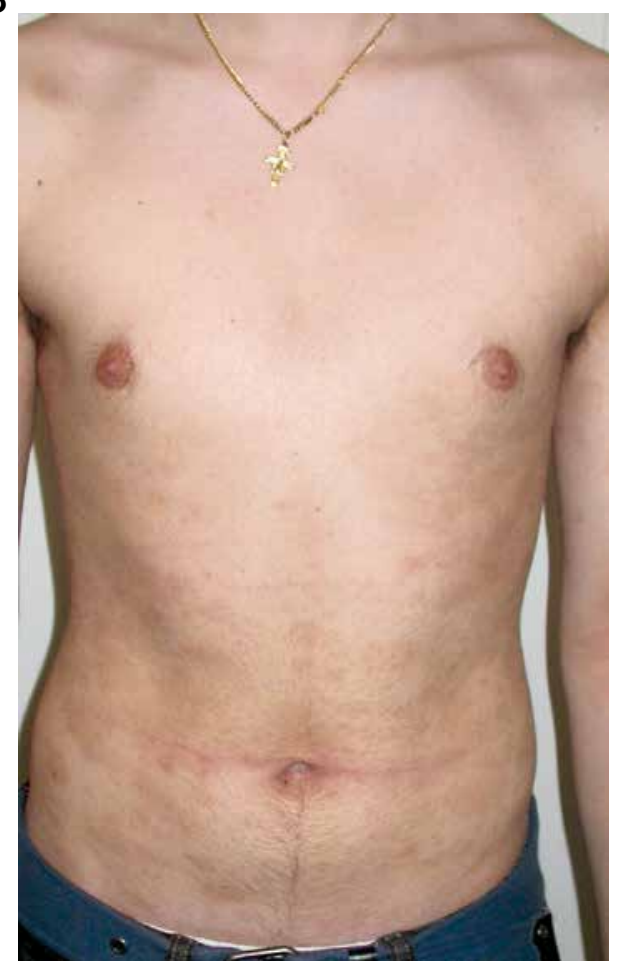

Figure I A, B. Erythema dyschromicum perstans. Grey-brownish macular hyperpigmentation on the skin of the trunk

of a skin biopsy revealed discrete vacuolization of the stratum basale and scattered melanophages (Fig. 2). Based on the clinical and histopathological features, the diagnosis of EDP was made. Photoprotection and emollients were prescribed. The cutaneous lesions were found to have regressed within 4 months (Figs. $3 \mathrm{~A}$ and $3 \mathrm{~B}$ ).

\section{DISCUSSION}

Erythema dyschromicum perstans was first described in 1957 by Ramirez [3]. Based on the clinical

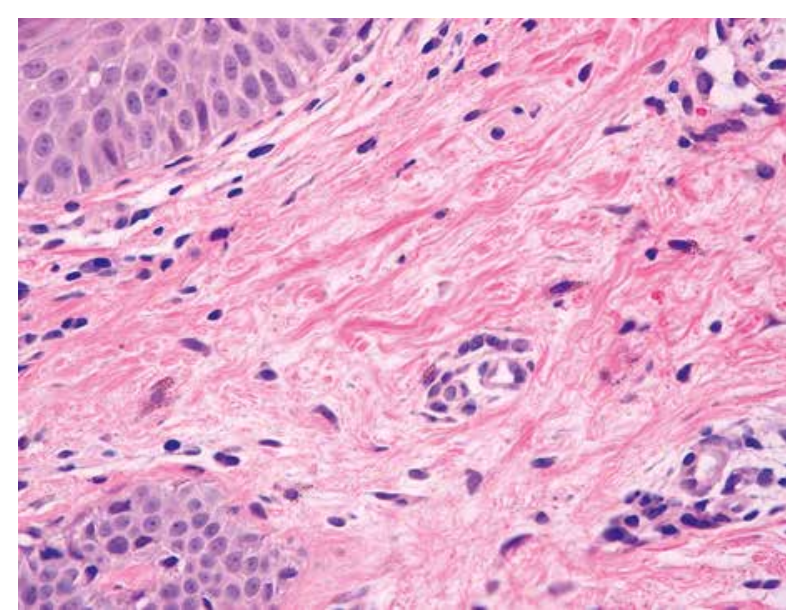

Figure 2. Erythema dyschromicum perstans - histopathologic feature: single melanophages in the papillary dermis presentation of skin eruptions the author originally termed the condition dermatosis cenicienta. Since that time, the disorder has been reported in medical literature under various names: ashy dermatosis, lichen planus pigmentosus, idiopathic eruptive macular pigmentation or los cencientos [2]. Erythema dyschromicum perstans is uncommon in the Caucasian population, and children make up only $8-10 \%$ of all EDP patients [4]. Erythema dyschromicum perstans lesions are manifested as asymptomatic greyish ashcoloured, occasionally brown-grey, patches with an erythematous peripheral margin, often barely distinguishable, measuring 1-2 $\mathrm{mm}$ in width. The patches usually have a symmetric distribution. The most common sites of involvement are the trunk and proximal arms and legs. Less frequently involved is the skin of the face and neck. Characteristically, the palms and soles, the scalp and mucous membranes are EDP-free [1]. Histopathological findings include the presence of a sparse perivascular lymphocytic infiltrate in the dermis, and numerous melanophages. At an early stage of skin involvement, typical features include vacuolization of keratinocytes in the basal layer, presence of cytoid bodies, lymphocytic epidermotropism and pigment incontinence [1].

The etiopathogenesis of the condition remains unclear. Several infectious agents have been proposed as implicated in the development of EDP, including viruses (hepatitis $C$ virus, human immunodeficiency 


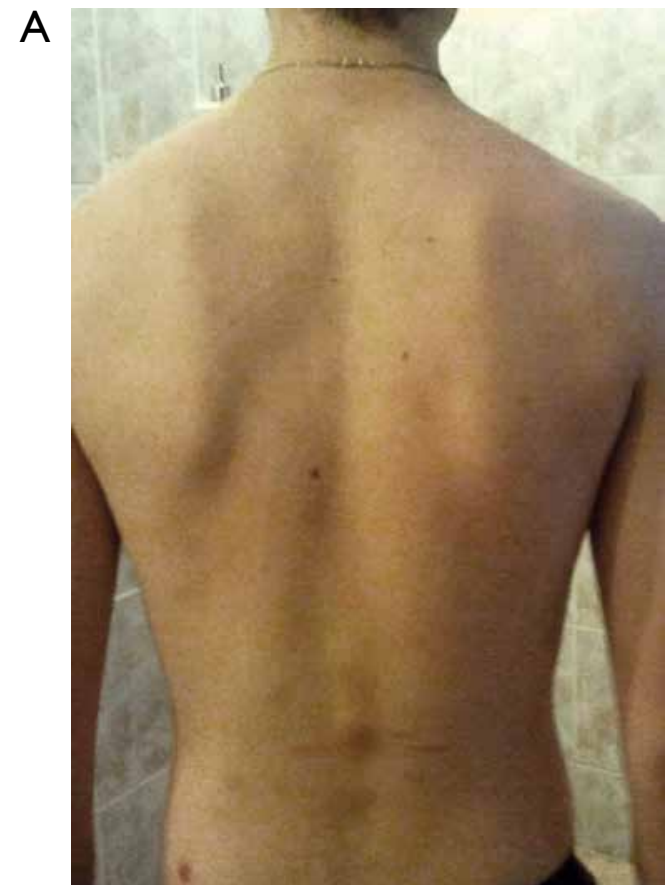

Figure $3 \mathrm{~A}, \mathrm{~B}$. Complete regression of the cutaneous lesions

virus) and parasites (whipworm infestation). There have been reports of EDP accompanying endocrinopathies (hypothyroidism) and vitiligo. Some authors have theorized that in some cases EDP is a variant of lichen planus. Toxic substances (pesticides, radiographic contrast media) and medications also seem to be major etiological factors. There have been cases of EDP linked to the treatment with sodium nitrite, benzodiazepines, chlorothalonil, ethambutol, omeprazole and antibiotics [1, 2, 4-9].

Because of unclear etiopathogenesis the treatment of EDP is difficult. There have been medical reports describing therapy with photoprotective, keratolytic, antimalarial and antihistamine agents, topical and systemic glucocorticosteroids, dapsone, antibiotics, griseofulvin, clofazimine, ascorbic acid, laser treatment and chemical peels $[1,5]$. The multitude of therapeutic options attests to their limited efficacy. In the case discussed here, because of the moderate severity of skin involvement and absence of any subjective symptoms, a wait-and-see attitude was adopted.

Inflammatory bowel diseases, CD included, have a very broad range of dermatological symptomatology. Skin lesions accompanying these conditions are identified in between $2 \%$ and $34 \%$ of all patients [10]. The most common dermal manifestations of $\mathrm{CD}$ are pyoderma gangrenosum and erythema nodosum, however medical literature also includes accounts of a number of other skin conditions [10]. Sładek and Ćmiel [11], who examined clinically a total of 146 children with $\mathrm{CD}$, identified dermatological manifestations of the disease (aphthosis and erythema no-
B

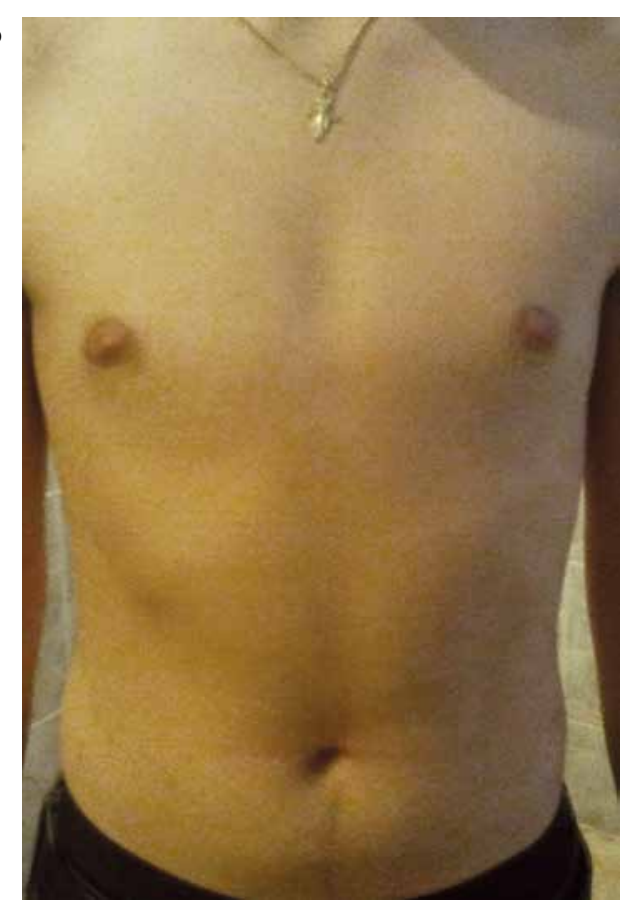

dosum) in $26.7 \%$ of their patients. Studies by Mierzwa et al. [12] corroborate the finding that aphthosis is the most common dermo-mucosal symptom accompanying $C D$ in children and adolescents.

The introduction of biologic medications has been a breakthrough in the therapy of rheumatic, gastrointestinal and dermatological diseases. Due to their widespread use, the spectrum of adverse effects caused by biologic drugs is quite well-known. Lee et al. [13] observed adverse skin reactions in 35 out of 150 patients $(23.3 \%)$ treated with anti-TNF- $\alpha$ agents due to rheumatic conditions. In $45.7 \%$ of cases cutaneous reactions presented as psoriatic or eczematous lesions. Viral, bacterial or fungal infections were confirmed in $37.1 \%$ of study patients. There were also isolated cases of dermatitis herpetiformis, leukocytoclasis vasculitis and alopecia areata. Other reported skin abnormalities accompanying biological therapy include pustular lesions, non-specific vesicular skin eruptions and necrotizing fasciitis [14, 15]. Moreover, biologic drugs have a relatively high potential for the induction of lupus erythematous [16]. A review of medical literature has revealed one case of hyperpigmentations occurring during anti-TNF- $\alpha$ treatment. Kelley et al. [17] reported acquired dermal melanocytosis in a psoriasis patient treated with infliximab. An important report in the context discussed here is that by Bovenschen et al. [18]. The authors described three cases of eruptive benign melanocytic naevi in $\mathrm{CD}$ and psoriasis patients who were treated with infliximab, etanercept and alefacept. Similar skin lesions are also observed in other patients with ha- 
ematological or iatrogenic immunosuppression [19]. According to what seems to be the most convincing pathogenetic hypothesis, immune suppression affects the expression of the melanocyte-stimulating hormone, which in turn has an impact on neogenesis and melanogenesis [18]. The theory also seems to apply to EDP, especially in the light of the fact that the condition has been observed in immune-incompetent patients [6].

The authors have not identified medical reports about any potential link of EDP with CD, and infliximab or other TNF- $\alpha$ blockers. It is not possible to establish unambiguously whether the patient's cutaneous lesions were associated with CD or infliximab therapy. A coincidental link cannot be ruled out, either. Complete remission of cutaneous lesions seen after the discontinuation of treatment seems to suggest a correlation between EDP and biological therapy, especially that histopathological findings were consistent with the residual phase of the disease. Since EDP often presents as a mild, asymptomatic, transient and often subclinical condition, patients may have a tendency not to report any symptoms. Also in the case discussed here neither the patient himself nor his family regarded the skin lesions as a major health problem.

Summing up, according to the authors' knowledge the case presented above, which is interesting both from the dermatological and gastroenterological perspective, is also the world's first report about EDP coexisting with infliximab-treated CD. The case corroborates the link existing between the two medical disciplines, and expands the knowledge of this rare and little known condition.

\section{References}

1. Lange M., Trzeciak M., Sokołowska-Wojdyło M., Trzeciak M., Roszkiewicz J.: Erythema dyschromicum perstans (ashy dermatosis) - opis przypadków. Przegl Dermatol 2011, 98, 322-327.

2. Zaynoun S., Rubeiz N., Kibbi A.G.: Ashy dermatosis a critical review of the literature and proposed simplified clinical classification. Int J Dermatol 2008, 47, 542-544.

3. Ramirez C.O.: Los cenescientos: problema clinico. [w:] Proceedings of the first Central American Congress of Dermatology 1957, 122-130.

4. Silverberg N.B., Herz J., Wagner A., Paller A.S: Erythema dyschromicum perstans in prepubertal children. Pediatr Dermatol 2003, 20, 398-403.

5. Torrelo A., Zaballos P., Colmenero I., Mediero I.G., de Prada I., Zambrano A.: Erythema dyschromicum perstans in children: a report of 14 cases. JEADV 2005, 19, 422-426.

6. Nelson M.R., Lawrence A.G., Staughton R.C., Gazzard B.G.: Erythema dyschromicum perstans in an HIV antibody-positive man. Br J Dermatol 1992, 127, 658-659.

7. Sirvastava N., Solanki L.S., Chand S., Garbyal R.S., Singh S.: Ashy dermatosis-like pigmentation due to ethambutol. Indian J Dermatol Venereol Leprol 2008, 74, 281-282.

8. Ramirez-Hernandez M., Martinez-Escribano J.A., Martinez-Barba E., Alcolea-Rubio L.A., Ibarra-Berrocal I.J.: Cu- taneous hyperpigmentation induced by omeprazole mimicking ashy dermatosis. JEADV 2006, 20, 584-587.

9. Jabłońska S.: Ingestion of ammonium nitrate as a possibile cause of erythema dyschromicum perstans (ashy dermatosis). Dermatologica 1975, 150, 287-291.

10. Yüksel I., Başar O., Ataseven H., Ertuğrul I., Arhan M., Ibiş M. $\mathbf{i}$ inni: Mucocutaneous manifestations in inflammatory bowel disease. Inflamm Bowel Dis 2009, 15, 546-550.

11. Sładek M., Ćmiel A.: Charakterystyka obrazu klinicznego 146 nowo rozpoznanych przypadków pediatrycznych choroby Leśniowskiego-Crohna. Prz Gastroenterol 2011, 6, 102-109.

12. Mierzwa G., Czerwionka-Szflarska M., Bała G.: Choroba Leśniowskiego-Crohna u dzieci i młodzieży. Prz Gastroenterol 2007, 2, 22-6.

13. Lee H.H., Song I.H., Friedrich M., Gauliard A., Detert J., Röwert J. i inni: Cutaneous side-effects in patients with rheumatic diseases during application of tumour necrosis factor-alpha antagonists. Br J Dermatol 2007, 156, 486-491.

14. Devos S.A., van den Bossche N., de Vos M., Naeyaert J.M.: Adverse skin reactions to anti-TNF-alpha monoclonal antibody therapy. Dermatology 2003, 206, 388-390.

15. Chan A.T., Cleeve V., Daymond T.J.: Necrotising fasciitis in a patient receiving infliximab for rheumatoid arthritis. Postgard Med J 2002, 78, 47-48.

16. Sobjanek M., Wilkowska A., Sokołowska-Wojdyło M., Michajłowski I., Roszkiewicz J.: Kontrowersje wokół rozpoznania tocznia rumieniowatego indukowanego lekami anty-TNF- $\alpha$ u pacjentki leczonej z powodu łuszczycy Przegl Dermatol 2012, 99, 605-610.

17. Kelley B.P., Doherty S.D., Calame A., Hsu S.: Acquired dermal melanocytosis of the hand at the site of treated psoriasis. Dermatol Online J 2009, 15, 2.

18. Bovenschen H.J., Tjioe M., Vermaat H., de Hoop D., Witteman B.M., Janssens R.W. i inni: Induction of eruptive benign melanocytic naevi by immune suppressive agents, including biologicals. Br J Dermatol 2006, 154, 880-884.

19. Alaibac M., Piaserico S., Rossi C.R., Foletto M., Zacchello G., Carli P. i inni: Eruptive melanocytic nevi in patients with renal allografts: report of 10 cases with dermoscopic findings. J Am Acad Dermatol 2003, 49, 1020-1022.

Received: 8 I 2014

Accepted: 27 I 2014 